\title{
Recipe for a good research laboratory
}

\section{A Japanese laboratory illustrates the benefits of autonomy (and the responsibility that goes with it) and budgetary predictability in creating a framework for productive research.}

Sagamihara. To celebrate the beginning of the next millennium, UNESCO or some such body might think of awarding a prize to the best laboratory in the world. What could be a better celebration of a century's remarkable achievement and a more powerful reinforcement of still timorous hopes for the future than such a recognition of well ordered and imaginative research? (If UNESCO thinks well of the idea, it had better get moving quickly; there is not much time left.) But the chances are that the prize would even then go to the Institute for Space and Astronautical Science (ISAS) at this site West of Tokyo, which is contiguous with Metropolitan Tokyo even if it is confusingly in a different prefecture.

ISAS has significantly interesting roots. It owes its existence to the early post-Sputnik enthusiasm of academics at the University of Tokyo for space research of almost any kind. (The first experiment, organized by the Department of Industrial Technology, was the horizontal launch of a rocket $23 \mathrm{~cm}$ long to confirm ideas about drag in the lower atmosphere.) By 1964, a group of academics from the physics department and the engineering faculty had pooled resources to build and launch first sounding rockets, then satellites.

Ten years ago, their successors moved from a scruffy building in Tokyo proper to splendidly functional buildings on this site, which was previously a US military base and which, by legend, was one at which Japanese researchers were within an ace of developing a surface-to-air missile (based on infrared guidance) when bombs fell on Hiroshima and Nagasaki in 1946. What follows are notes compiled during a threeday visit (for a different purpose) last week which may throw some light on why some laboratories are better than others.

The constitution helps. ISAS was created as a research institute within the University of Tokyo, which has until recently been the Japanese way of supporting some university research well while neglecting the rest of it. That means that the institute has from the outset been supported exclusively by the Ministry of Education. Its senior members were invariably members of the Tokyo faculty; now there is a sprinkling of people from the universities of Nagoya, Osaka and Kyoto.

The most striking mark of the institute's success is that, in the past 20 years, it has launched 22 Earth satellites entirely with its own resources and, during that long period, has had only one failure (in the late 1970s).
The present goal is to launch one satellite a year, either in January or July when downrange restrictions in the interests of Japan's vociferous fishermen are suspended, but there were two in 1985 in preparation for the rendezvous the following year with Halley's comet. What rocket-launching organization would not give its eye-teeth for such a record of reliability?

That numerical index does not fully reflect the academic benefits of this predictability. But it is now, for example, institute policy to launch one X-ray satellite every four to six years. The argument is that, having encouraged the growth of an X-ray astronomy community in Japan (nearly 100 people, two-thirds of them students), it is only proper to cater for its interests with fresh data and for its aspirations by designing ever more advanced telescopes.

Ingenuity, just sheer neatness, is another characteristic of what goes on here. ISAS, for example, has been the most diligent of space research organizations in the exploitation of the momentum a spacecraft can pick up through a close encounter with some planetary object to win extra lifting power (mass into a low orbit) from the rockets available. As early as 1990, a satellite called Hiten was put into an eccentric orbit around the Earth in such a way that, after eight successive close encounters with the Moon, it occupied an eccentric orbit reaching out nearly three times as far as the radius of the lunar orbit.

More recently, the satellite called Geotail, launched in 1992 by a US rocket from NASA's Kennedy Space Center in Florida, is now making the most detailed observations yet of the solar wind in the complicated wake created by the Earth's motion around the Sun. Geotail, already further away than Hiten in its eccentric orbit about the Earth, is still alive.

But ingenuity is everywhere. There is, for example, a complicated bundle of wires that can be wound on what looks like a large fishing-reel that will, by means of moveable hinges, turn into a rigid boom when it is unwound. Six such devices will be needed for the 8-m radiotelescope now being planned for launching in 1996. That will be the world's first dedicated radiotelescope in orbit, and the first serious use of a space component for Very Long Baseline Interferometry (VLBI). Perhaps the people who gave the rest of us origami are best equipped to fold an $8-\mathrm{m}$ telescope into an instrument bay only $2.4 \mathrm{~m}$ in diameter.
The engineers seem confident that it will work. They can, after all, point to the success of the extendible optical bench it was necessary to use to fit four parallel X-ray telescopes into the fourth X-ray satellite Asca, launched in February this year. In the event, the collapsed version of the structure did extend itself to give the telescopes the planned focal length of $3.5 \mathrm{~m}$.

Patience is another of ISAS's virtues. Thus the engineers use telemetry data from rockets during their launch phase not simply to check that they are still intact, but also to improve the performance of their successors. The result is that the lifting power of the rockets now being used (solid-fuelled three-stage rockets whose diameter has been restricted to $1.2 \mathrm{~m}$ ) has been increased threefold over the years. People seem confident that the new rocket (twice as wide, but not much longer) being developed (and to be used first for launching the radiotelescope) will similarly be improved.

Why does all this work so well? There are several explanations. First, there is a separation of functions between ISAS and the more recently created National Space Development Agency (NASDA), whose remit is exclusively the development and launching of applications satellites (for communications, for example). Among other things, that means that space science is not cut back when applications work runs over budget.

Second, ISAS gains extra autonomy from being comprehensively in charge of everything it does, from engineering design to operations.

Third, engineering is as much honoured as science. In the project teams constituted afresh for each satellite launch (usually five years in advance), engineers and scientists work as equal partners. To rub the point in, directors-general are chosen alternately from the two sides of the church. Graduate students (about 100 in total) are expected to muck in with the rest, and may well find themselves responsible for executing some mid-orbit course correction from the modest control room.

The other strength of ISAS is its human scale. The present staff is fewer than 300 (who ensure that the 100 graduate students keep their noses to the grindstone). Senior people may find themselves carrying responsibility for two or three separate functions, in flat contradiction of what the management schools forever preach. Inevitably, official working hours are an unattainable dream. It could only happen in Japan.

John Maddox 